STUDIA HUMANITATIS JOURNAL, 2022, 2(I), pp. 22I-234

ISSN: 2792-3967

D01: https://doi.org//0.5370I/shj.v2il.40

Debate / Controversy

\title{
SITUACIÓN DE LAS AGRUPACIONES FOLKLÓRICAS EN TIEMPOS DE PANDEMIA ${ }^{1}$
}

\author{
SITUATION OF THE FOLKLORIC GROUPS IN TIMES OF PANDEMIC
}

\author{
Víctor Jesús Cobo Franco \\ Investigador independiente \\ ORCID: 0000-0002-285I-3942 \\ vjcobo@hotmail.com
}

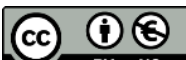

\section{| Resumen |}

Desde la llegada del COVID-19 a nuestro pais y la declaración del estado de alarma, los colectivos dedicados a la música y danza tradicional vieron como sus actividades (ensayos, actuaciones, festivales) se detuvieron de manera inminente, pero durante este tiempo de pandemia no han estado inactivos pues han sido muchas las actividades y contenidos que han ofrecido a la sociedad de forma telemática a través de múltiples plataformas digitales, adaptándose así a la nueva normalidad, para continuar con uno de sus objetivos prioritarios como es la difusión y el acercamiento al público de los bienes culturales intangibles que poseen en su saber. En el presente debate se refleja la visión en primera persona de la situación de estos colectivos de música y danza tradicional más conocidos como agrupaciones folklóricas o coros y danzas, analizando la situación de Coros y Danzas La Nacencia del Centro Extremeño en Alcalá de Henares y enriqueciendo además el debate con las entrevistas realizadas a la Asociación de Coros y Danzas Rosa del Azafrán (Consuegra-Toledo), Grupo de Danzas San Sebastián de Reinosa (Reinosa-Cantabria), Asociación Folclórica e Cultural Orballo (Pontedeume-Coruña), Asociación de Coros y Danzas de Cieza (Cieza-Murcia) y Asociación de Coros y Danzas Despertar El Ayer (Villanueva de Alcardete-Toledo), cuyas actividades llevadas a cabo durante este tiempo han buscado nuevas fórmulas y actividades para intentar mantener la música y danza tradicional en el imaginario de la sociedad actual.

Palabras clave: Danza tradicional, Folklore, Folclore, Pandemia, Ensayos, Festivales, Artes escénicas.

\section{Abstract}

Since the arrival of COVID-19 in our country, the groups dedicated to traditional music and dance saw their activities (rehearsals, performances, festivals) come to a halt. However, throughout the pandemic they have not been inactive. They have adapted to the new normal by offering content remotely through multiple digital platforms. They continue to perform their primary objective by sharing with the public the intangible cultural assets that they possess in their knowledge: the traditional music and dance. The debate reflects a first-person view of the current situation of these traditional music and dance groups, better known as folk groups or Choirs and Dances, analyzing the situation of Coros y Danzas La Nacencia del Centro Extremadura in Alcala de Henares and also enriching the debate with interviews with the Rosa del Azafrán Choirs and Dances Association (Consuegra-Toledo), San Sebastián de Reinosa Dance Group (Reinosa-Cantabria) Orballo Folkloric and Cultural Association (Pontedeume-Coruña), Association of Choirs and Dances Cieza (Cieza-Murcia) and Association of Choirs and Dances Despertar El Ayer (Villanueva de Alcardete-Toledo), whose activities carried out during this time new strategies and activities to keep traditional music in the imaginary of today's society.

Keywords: Traditional dance, Folklore, Pandemic, Rehearsals, Festivals, Performing arts.

Recibido/Received: 23/| |/202|

Aceptado/Accepted: 21/0I/2022 


\section{| Introducción |}

La COVID-19 parecía que nunca llegaría a España cuando su primer caso fue detectado en diciembre de 2019 en Wuhan (China). Veíamos a través de las noticias como el número de casos iba aumentando a la vez que aparecían nuevos casos en otros países. El virus se aproximaba a España, pero nunca creíamos que fuera a entrar en nuestro país y en caso de llegar, nunca sería tan grave -o al menos eso nos hacían creer- como realmente ha sido.

Actualmente, con la finalización del estado de alarma, se ha generado un clima de incertidumbre dentro de la nueva normalidad, pues las autoridades sanitarias han concretado una serie de criterios de salud pública de obligado cumplimiento y medidas de prevención que eviten la continuidad de la pandemia y el contagio de nuevas variantes de la COVID-19.

La pandemia ha afectado a todos los ámbitos sociales. Ha tenido una gran repercusión económica a nivel global pero también cabe destacar el "parón cultural" que ha sufrido el mundo de la cultura (artistas, compañías, técnicos, empresas del sector, etc.).

La situación actual en el terreno del arte y la cultura ha propiciado que los artistas tengan que buscar nuevas formas de compartir, enseñar y crear sus obras, así como otros procesos creativos (Colomer, 2021).

La situación actual en los colectivos dedicados al folklore ha dado lugar a que sus integrantes tengan que buscar nuevas fórmulas y vías para mostrar, compartir, promocionar y difundir la música y danza tradicional, en definitiva, reinventarse en tiempos de pandemia para continuar mostrando a la sociedad los bienes culturales que atesoran en sus colectivos y que forman parte del PIC de nuestro país.

El presente debate pretende explicar el panorama de estas agrupaciones de folklore durante la pandemia abordando la cuestión desde una perspectiva personal junto a una visión contrastada con diferentes agrupaciones de folklore de ámbito nacional.

\section{| ¿Qué hicieron los colectivos de folklore}

\section{al declararse la pandemia? |}

Ensayos de baile y rondalla semanales, clases en sus escuelas de folklore distribuidas en diferentes niveles, bien de baile como de música y cante, proyectos de nuevas grabaciones sonoras, actuaciones de los grupos titular, infantil y juvenil, nuevas puestas en escena tradicionales y con aires más renovadores, participación en festivales nacionales e internacionales, organización y preparación de viajes a otros países y comunidades autónomas, intercambios con otros colectivos, nuevos espectáculos para acercar la danza tradicional a todo tipo de público, nuevas ediciones de festivales nacionales e internacionales de folklore junto a la búsqueda de grupos participantes, reuniones con la concejalía de cultura, etc. Un colectivo siempre muy activo y que nunca se detenía hasta que todo se paró por la COVID-19. 
Al principio iban a ser quince días naturales. Dos semanas sin que los componentes de las agrupaciones pudieran reunirse en los locales de sus asociaciones para continuar con sus ensayos semanales y preparar todas las actuaciones y proyectos que tenían previstos para el 2020. Pero el estado de alarma se prolongó. Todas las expectativas de cada uno de los componentes se vieron frenadas por la pandemia. Estarían meses sin poder juntarse para realizar una de las cosas que más les gusta como bailar, cantar o tocar, en definitiva, para poder realizar sus ensayos. Además, estarían meses sin poder ponerse un traje y subir a un escenario a poner en valor los bienes culturales inmateriales que atesoran en sus colectivos, siendo éstos los portadores y transmisores de la tradición que han recibido de sus antepasados.

En la actualidad existen numerosos colectivos dedicados a preservar, difundir, transmitir y salvaguardar las danzas y los bailes que han sido transmitidos por sus predecesores. Estos colectivos tienen la misión de transmitir a futuras generaciones este legado que se ha ido manteniendo de generación en generación (Cobo, 2021).

Y no hay cosa que le guste más a un amante de la tradición, como son todas aquellas personas que forman parte de un grupo folklórico, que ponerse su indumentaria tradicional y echarse unos bailes o cantes sin importar el lugar. Pues lo mismo le da que sea en un gran teatro, romería, festival o plaza del pueblo, que lo que le gusta a un buen "folklórico" es mostrar la riqueza de la música y danza tradicional de su región. Pero tanto actuaciones como festivales y cualquier otro evento relacionado con las artes escénicas se suspendieron y estos colectivos vieron cómo se interrumpía su actividad.

Han sido muchas las asociaciones las que han visto truncados sus proyectos en 2020 pero también en 2021, pues han decidido esperar a retomar sus actividades hasta que la situación mejore debido a los múltiples rebrotes, variantes del virus, repuntes y oleadas que está habiendo en España.

Existen 2001 colectivos, según el Registro de Asociaciones del Ministerio del Interior, los dedicados a preservar, mantener, difundir y salvaguardar la cultura tradicional. Muchos más que los establecidos en el imaginario colectivo de la sociedad española. (Cobo, 2021).

\section{| Un colectivo siempre activo en constante evolución |}

Pero si la tradición está en constante evolución, las asociaciones de folklore, aquellas dedicadas a la música y danza tradicional, no iban a ser menos. Ante este panorama que se les presentaba de meses sin realizar ningún tipo de evento, los colectivos pusieron su imaginación al servicio de la tradición e idearon la manera de estar presentes y visibles ante la sociedad. Mostrándose activos frente al "parón cultural”, cercanos ante la soledad de muchas personas que se encontraban aisladas en sus hogares $y$, como portadores de un patrimonio intangible heredado de sus antecesores, transmitirían éste a través de nuevas actividades y diferentes vías de comunicación, haciendo uso de las Tecnologías de la Información y de la Comunicación. 
Para mí como director de Coros y Danzas La Nacencia, siempre he tenido la idea durante el confinamiento de seguir manteniendo contacto, aunque no fuera de manera presencial, con todos los integrantes del grupo principal grupo infantil y senior a través del grupo de WhatsApp para hacerles partícipes de las diferentes propuestas y actividades que se proponían desde la directiva de la agrupación. Dichas actividades tenían como propósito seguir estando en contacto con todos los integrantes del grupo, los cuales, podían o no participar, pues su colaboración en ellas era de manera voluntaria; conocer el estado de salud de los componentes y saber que todos estaban bien además de ayudar a llevar mejor el momento de aislamiento y soledad que algunos integrantes de la agrupación tenían durante el confinamiento pues estas actividades, ayudarían a evadirse del difícil momento que estábamos pasando en nuestro país.

Más concretamente, el grupo de Coros y Danzas La Nacencia ha realizado numerosas actividades durante todos estos meses de "parón cultural". Aunque no ha participado en ninguna actuación presencial, no ha acudido a ningún festival presencial y no ha llevado a cabo en 2020 y 2021 su propio Festival Cervantino de Música y Danza Tradicional han sido muchas las actividades y colaboraciones las que ha realizado durante todos estos meses con la intención de mantener siempre activa la agrupación, así como a sus componentes.

Las actividades, festivales y actuaciones llevadas a cabo de manera online han sido las siguientes:

En el mes de abril de 2020:

\section{1) Coros y Danzas La Nacencia jse queda en casa!}

- Vídeo invitando a quedarse en casa junto a mensajes positivos y de apoyo y esperanza para los enfermos de COVID-19. Todos los componentes aparecían mostrando la riqueza de la indumentaria tradicional extremeña. El vídeo comenzaba con el siguiente texto:

Porque no hay nada que nos guste más que juntarnos todos en un ensayo para subirnos después a un escenario a disfrutar de nuestra música y danza tradicional extremeña. Pero mientras tanto Coros y Danzas La Nacencia se queda en casa esperando a que muy pronto esto finalice y podamos de nuevo ponernos nuestros trajes para bailar, entonar nuestras voces para cantar y afinar los instrumentos para tocar" 2 .

\section{2) Día Internacional de la Danza}

- Vídeo para celebrar el Día Internacional de la Danza. Músicos, bailarines y cantantes aparecen en el vídeo bailando, tocando o cantando desde sus hogares la Jota de Romería de la Coronada (Badajoz) vestidos con sus trajes extremeños o con la camiseta de la agrupación o del festival. ${ }^{3}$ 
- Participación en el vídeo del Día Internacional de la Danza realizado por FACYDE junto al resto de asociaciones federadas ${ }^{4}$.

En el mes de mayo de 2020:

1) Fiestas desde casa 2020

- Actuación de Coros y Danzas La Nacencia en la programación virtual de las fiestas de San Isidro en Alcalá de Henares.

En junio de 2020:

\section{1) I Festival Internacional de Folclore Ciudad de Granada}

- Participación en el I Festival Internacional de Folclore Ciudad de Granada realizado de manera virtual por el Grupo de Coros y Danzas de Granada 5 .

\section{2) Día de la Música}

- Vídeo para celebrar el Día de la Música con grabaciones realizadas desde casa. Cantantes y músicos interpretan diferentes canciones tradicionales extremeñas 6 .

\section{3) Fiestas desde casa 2020}

- Actuación de Coros y Danzas La Nacencia en la programación virtual de las fiestas de San Juan en Alcalá de Henares ${ }^{7}$.

En julio de 2020:

\section{1) Suite de la Sía durante la pandemia}

- Colaboración de varios componentes de la agrupación junto a otros integrantes de otros colectivos de folklore a nivel nacional en la Suite de la Sía de Vanesa Muela durante la pandemia ${ }^{8}$.

En agosto de 2020:

\section{1) Día Internacional del Folklore}

- Realización de una felicitación para celebrar el Día Internacional del Folklore.

\footnotetext{
${ }^{4}$ https://www.facebook.com/FACYDE/videos/160674132021539

5 https://www.youtube.com/watch?v=EJ1LphnoQH0

${ }^{6} \mathrm{https://www.facebook.com/lanacencia.folkloreextremeno/videos/589863068613401}$

${ }^{7}$ https://www.youtube.com/watch?app=desktop\&v=T3dTYb5S9ak\&feature=youtu.be\&fbclid=IwAR2brfDRBvqOlx5ZPKGtkxC8rPF VNg51mxvuTA00QbclCr38BQbK4Uw5cTA

${ }^{8}$ https://www.youtube.com/watch?v=ePuDNuOTjFw
} 
En septiembre de 2020:

\section{1) Día de Extremadura}

- Vídeo realizado para celebrar el Día de Extremadura con imágenes del espectáculo "Mujeres Extremeñas" e interpretando el Himno de Extremadura por rondeña versión del grupo extremeño Chulumi ${ }^{9}$.

En octubre de 2020:

1) $58^{\circ}$ Edición Festival Nacional Rosa del Azafrán

- Vídeo realizado por varios componentes ataviados con sus trajes regionales y enviando un mensaje de apoyo a la $58^{\circ}$ Festival Nacional Rosa del Azafrán de Consuegra.

En noviembre de 2020:

\section{1) Jornadas Culturales Virtuales Extremeñas del Centro Extremeño}

- Celebración de las Jornadas Culturales Extremeñas del Centro Extremeño en Alcalá de Henares de manera virtual en donde Coros y Danzas La Nacencia participa haciendo una selección de diferentes actuaciones a lo largo de la historia del grupo ${ }^{10}$.

2) Día de Santa Cecilia, patrona de los músicos

- Realización de una felicitación para celebrar el Día de Santa Cecilia, patrona de los músicos.

En diciembre de 2020:

\section{1) Felicitación navideña}

- Vídeo realizado para felicitar las fiestas con villancicos extremeños interpretados por el coro de la agrupación junto a una selección de fotos de la agrupación ${ }^{11}$.

Durante febrero, marzo y abril de 2021.

\section{1) Reto \#YoMeVistoDeFolclóricoEnCasa}

- Se lanza un reto divertido a todos los componentes de la agrupación e invitando a todos aquellos compañeros de otras agrupaciones que quisieran sumarse al \#YoMeVistoDeFolclóricoEnCasa. El reto consiste en hacerse una fotografía con un traje regional extremeño realizando tareas cotidianas en casa. Durante tres meses se subió una imagen por día a las redes sociales de la agrupación y el reto culminó con un vídeo de las fotografías publicadas. Con esta iniciativa además se pretendía dar a conocer la indumentaria extremeña ${ }^{12}$.

\footnotetext{
https://www.youtube.com/watch?v=jl6e-9aNxmA

https://www.youtube.com/watch?v=ixq_psRHTXQ

https://www.youtube.com/watch?v=fnpRA72INEU

${ }^{12}$ https://www.youtube.com/watch? $\mathrm{v}=$ liawKFwyMU0\&t=6s
} 
En abril de 2021:

\section{1) Día Internacional de la Danza}

- Vídeo para celebrar el Día Internacional de la Danza con fotos seleccionadas por todos los componentes ${ }^{13}$.

- Participación en el vídeo realizado por FACYDE para celebrar el Día Internacional de la Danza ${ }^{14}$.

En junio de 2021:

\section{1) Día de la Música}

- Vídeo para celebrar el Día de la Música con imágenes de los primeros ensayos de la rondalla realizados a finales de mayo ${ }^{15}$.

\section{2) Día de San Juan}

- Vídeo interpretando La Velada de San Juan durante la actuación realizada en julio de 2019 en el XII Festival Nacional Folklórico Alabarderos en Bolaños de Calatrava ${ }^{16}$.

En julio de 2021:

\section{1) Jornadas Folclóricas 2.1. Nazarenas Internacionales}

- Participación en las Jornadas Folclóricas 2.1. Nazarenas realizadas por el grupo de Dos Hermanas en Sevilla junto a otras agrupaciones ${ }^{17}$.

En agosto de 2021:

\section{1) Día Internacional del Folklore}

- Realización de una imagen con el pañuelo de Plumaje de Malpartida de Cáceres para celebrar el Día Internacional del Folklore.

En septiembre de 2021:

\section{1) Día de Extremadura}

- Vídeo realizado para celebrar el Día de Extremadura con imágenes del espectáculo "Bailando a los elementos" e interpretando la Jota de Guadalupe ${ }^{18}$.

Todas las actividades realizadas desde la agrupación y en aquellos eventos realizados por otros colectivos donde el grupo ha sido invitado a participar fueron difundidas a todos los componentes a través del grupo de WhatsApp para que la compartieran con amigos, familiares $y$ en sus redes sociales. Además, se publicaron en los diferentes perfiles sociales de la agrupación (Facebook, Instagram y Youtube) para llegar a una mayor

\footnotetext{
https://www.youtube.com/watch?v=LWgMiV9axhw

https://www.youtube.com/watch?v=sQ20mHbov4A

https://www.youtube.com/watch?v=znE0xMndXdk

https://www.youtube.com/watch?v=otazAPtxNfs

https://www.youtube.com/watch?v=-alsBx2Dwdw

https://www.youtube.com/watch?v=UIMjqw3RidU
}

SHJ, 2022, 2(I), pp. 22I-234. ISSN: 2792-3967 
audiencia y continuar así estando presente -aunque fuera de manera virtualcontribuyendo a la difusión de la música y danza tradicional.

En el caso de Coros y Danzas Rosa del Azafrán, las actividades llevadas a cabo según Valle fueron las siguientes:

- $58^{\circ}$ edición del Festival Nacional de Folklore Rosa del Azafrán de manera presencial los días 24 y 25 de octubre de 2021.

- Canto de la misa manchega en la festividad de la Virgen de la Esperanza el 20 de diciembre de 2020.

- Tradicional petición del aguinaldo la tarde de Nochebuena de 2020.

- Representación del grupo en el Festival Internacional Folk del Mundo de Jaén el 10 de julio de 2021.

- Canto de una boda el 24 de Julio de 2021.

Mientras que las actividades realizadas por el Grupo de Danzas San Sebastián de Reinosa fueron un par de reuniones virtuales, se realizó un vídeo con la jota campurriana por el Día Internacional de la Danza, se hizo un collage de indumentaria campurriana desde nuestras casas, se realizó un vídeo conmemorativo por el Día de San Sebastián de 2021 y se enviaron algunos vídeos explicativos con toques de pandereta entre los alumnos (Arce, 2021).

También hay que mencionar las publicaciones virtuales realizadas por la Asociación Folclórica e Cultural Orballo, así como el canto de misas manchegas en diferentes eventos locales, pasacalle de boda y los mayos por Coros y Danzas Despertar el Ayer durante el tiempo que estuvieron sin ensayos.

En definitiva, los colectivos de folklore buscaron desde un primer momento diversas fórmulas para que su actividad no se viera interrumpida por la pandemia, creando así nuevos productos y fórmulas para que la música y la danza tradicional continuara.

\section{| ¿Cómo se han retomado los ensayos? |}

Cuando el estado de alarma llega a su fin el 9 de mayo de 2021, después de un estado excepcional que se ha decretado tres veces durante la pandemia, los grupos de folklore a petición de sus componentes comienzan a plantearse retomar sus actividades con mucha prudencia, adoptando todas las medidas sanitarias.

El grupo de Coros y Danzas La Nacencia retoma sus ensayos de rondalla a finales de mayo de 2021 pero no lo hace en su sede habitual. Se solicita a la Concejalía de Cultura de Alcalá de Henares un espacio al aire libre donde poder mantener el metro y medio de distancia entre músicos y cantantes. La concejalía proporcionó un espacio abierto situado dentro de la propia Concejalía de Cultura para poder llevar a cabo los ensayos, adoptando por parte de los componentes todas las medidas de prevención. Los ensayos de baile, sólo se retomarán los del grupo titular a mediados de junio y se realizarán a la par con la rondalla hasta las primeras semanas de julio, pues al no participar en ningún 
festival ni actuación, se volverán a interrumpir por vacaciones hasta que se retoman nuevamente en octubre.

Los hábitos adquiridos de ensayos semanales, al verse interrumpido por la pandemia han cambiado y los ensayos de baile, al no tener actuaciones previstas, han tenido un bajo índice de participación con respecto a los realizados con anterioridad a la COVID-19. Y aunque la agrupación ha sido invitada a participar en diferentes festivales de ámbito nacional durante el periodo veraniego, se ha declinado la invitación al no haber un determinado número de componentes para realizar una digna actuación ya que existía miedo a los contagios y no todos los componentes estaban vacunados.

En Coros y Danzas Rosa del Azafrán en una primera etapa tras el primer confinamiento, los ensayos se reanudaron el 4 de septiembre de 2020 con motivo de la preparación de la $58^{\circ}$ edición del Festival Nacional de Folklore Rosa del Azafrán. El día 25 de octubre, cuando se celebró la gala principal del festival, se decretaba el estado de alarma en España, por lo que de nuevo quedaba suspendida toda actividad prevista, incluidos los ensayos.

El 18 de junio de 2021 volvieron a reanudarse los ensayos. En principio solo un día por semana en el caso del cuerpo de baile y de dos días en el caso de la rondalla. En relación con las escuelas, estas retomaron su actividad por niveles, estableciendo un solo día de ensayo a la semana. Cada día dedicado a una disciplina y nivel.

Tras meses de inactividad, los componentes han cambiado sus hábitos sociales y de ocio. Lo que antes era prioritario, ahora no lo es tanto. El sedentarismo causado por la pandemia, los nuevos hábitos y los cambios en las relaciones sociales, hacen que la asociación no termine de arrancar con fuerza. La reanudación de los ensayos vino reivindicada por los propios miembros de grupo, que en el mes de mayo solicitaron reiteradamente la vuelta a los ensayos (Valle, 2021).

El Grupo de Danzas San Sebastián de Reinosa ha retomado sus ensayos en diferentes momentos: en el periodo septiembre-octubre de 2020, de marzo de 2021 a principios de abril de 2021 y de mediados de mayo de 2021 hasta la actualidad.

Con la parada el ayuntamiento cerró el centro cultural donde ensayábamos habitualmente y nos han pasado a un pabellón municipal de mayores dimensiones, con un volumen de aire que se podría asemejar a estar ensayando en el exterior y que se ventila continuamente. En la actualidad, se han realizado cuatro actuaciones y están en previsión dos más ya cerradas (Arce, 2021).

Para conocer la aceptación de los componentes con respecto a retomar los ensayos durante esta situación de pandemia se realizó un sondeo entre los componentes para retomar los ensayos y para comprometerse a las actuaciones que pudieran salir durante el verano. Salió un grupo de 16 personas estables además de músicos y se ha contado con la colaboración de otras personas externas para realizar algunas actuaciones.

Según ha ido avanzando este periodo veraniego, este número se ha incrementado y a medida que avanza la vacunación la confianza es mayor pensando que en septiembre es SHJ, 2022, 2(I), pp. 22I-234. ISSN: 2792-3967 
posible que se retome con gran normalidad los ensayos, no tanto en protocolo de funcionamiento sino como de asistencia (Arce, 2021).

La Asociación Folclórica e Cultural Orballo reinició sus ensayos en septiembre de 2020 y se suspendieron en noviembre de ese mismo año al empeorar la incidencia COVID19 en la zona y desde entonces los ensayos no se han reanudado. Con respecto a la aceptación de los componentes de retomar los ensayos existe menos motivación a la hora de retomar rutina de ensayos. Negativa a participar en actividades sobre todo las personas que aún están sin vacunar (Martínez, 2021).

Coros y Danzas de Cieza retoma sus ensayos a mediados de junio de 2021, con prudencia y limitándose sólo a ensayar. Y según Saorín la participación y aceptación a retomar los ensayos es muy buena al incorporarse a los ensayos un $70 \%$ de los componentes.

Coros y Danzas Despertar el Ayer decide retomar sus ensayos en mayo de 2021 con actitud proactiva y prudente tras tomar la decisión de realizar el Festival en consenso con el Ayuntamiento, se procedió a iniciar los ensayos, tomando las precauciones y medidas de seguridad adecuadas (Sanz, 2021).

Los colectivos siempre han querido retomar sus ensayos a pesar de interrumpirse en varios momentos por cómo evolucionaba la COVID-19. Parece que en los colectivos no se alcanza el índice de participación que había en los ensayos anteriores a la pandemia y es una situación preocupante ya que sus integrantes podrían desligarse de la asociación al encontrar otros hábitos de ocio y cambios en las relaciones sociales durante este tiempo. Este problema iría en detrimento de los colectivos de folklore que podrían ver reducido el número de componentes.

\section{Medidas adoptadas al retomar los ensayos |}

Cuando Coros y Danzas La Nacencia retoma sus ensayos una de las medidas adoptadas e indicada desde la Concejalía es saber previamente qué componentes van a acudir. Deberán realizar lavado de manos con gel hidroalcohólico, acudir con mascarillas FPP2 y mantener la distancia de seguridad de metro y medio. Durante los ensayos tampoco se puede compartir ningún tipo de instrumentos de la agrupación (tamboril, almirez, mortero, pandereta...) y en caso de compartirlos, tenían que ser desinfectados antes de pasar a otro componente. Cada músico debía acudir con su instrumento propio, atril y partituras. Con respecto al baile, además de tener en cuenta las medidas preventivas anteriormente citadas, se evitan los bailes y danzas de contacto y en caso de realizarse, los componentes debían desinfectarse las manos antes y después de su ejecución.

Además, los ensayos estarán supeditados al transcurso de la situación sociosanitaria del momento y se adoptarán las reglas generales sociales como la utilización de mascarilla obligatoria tanto en los ensayos como en las actuaciones. 
En definitiva, todas las agrupaciones establecieron unas medidas sanitarias necesarias para desarrollar sus ensayos en un ambiente de protección y prevención de la salud de sus componentes.

\section{| ¿Festivales de folklore en tiempos de la COVID-19? |}

Este tipo de festivales con la COVID-19 verán como sus actividades se reducen e incluso desaparecen, centrándose en realizar únicamente las actuaciones de las agrupaciones participantes cuyo aforo será reducido.

El Instituto Nacional de Artes Escénicas y Música (INAEM) perteneciente al Ministerio de Cultura y Deportes publica el 12 de junio de 2020 la Guía de buenas prácticas para el reinicio de la actividad escénica y musical en España. Medidas y recomendaciones ante la crisis sanitaria de la Covid-19. Esta guía será el documento que servirá para reiniciar la actividad escénica y musical en España. Por tanto, será el documento referente también para los colectivos de música y danza tradicional al formar parte de las artes del espectáculo como se recoge en el art. 2 de la Convención para la Salvaguarda del Patrimonio Cultural Inmaterial y definiendo el concepto de patrimonio cultural inmaterial en el art. 1.

Con este documento de base, las agrupaciones de folklore tenían el punto de partida para comenzar a replantearse la realización o no de sus festivales nacionales 0 internacionales.

En el caso de Coros y Danzas La Nacencia, se decidió suspender el Festival Cervantino de Música y Danza Tradicional en 2020 y 2021. Este festival nació en el año 2016 y ha formado parte de las campañas realizadas por el Ministerio de Educación Cultura y Deportes en el IV Centenario de la muerte de Cervantes y en la campaña llevada a cabo por la UNESCO 2018 Año Europeo del Patrimonio Cultural. Ahora tiene puestas sus expectativas en que haya una mejor evolución en el desarrollo de la pandemia y poder desarrollar una nueva edición en el año 2022.

Este también es el caso de la Asociación Folclórica e Cultural Orballo que hubiera realizado en el año 2020 su $33^{\circ}$ edición del Festival Internacional de Folclore de Pontedeume. Dicho festival, el cual, nació en el año 1987, se suspendió tanto en 2020 como 2021 y esperando a poder llevar adelante una nueva edición en 2022.

Coros y Danzas Rosa del Azafrán celebró en octubre de 2020 su $58^{\circ}$ Festival Nacional de Folklore Rosa del Azafrán, el cual, nació en el año 1963. Esta edición se realizó de manera presencial en dos jornadas.

El planteamiento de la agrupación es volver a realizar en octubre de 2021 una nueva edición, siendo ésta de manera presencial y con grupos invitados. Todo dependerá cómo se encuentre la situación por la pandemia y el número de casos cuando se aproxime la fecha, aunque la intención es realizarlo al menos como el año pasado, con la participación de al menos un grupo y si las circunstancias lo permiten, se estudiará la posibilidad de aumentar el número de grupos participantes.

SHJ, 2022, 2(I), pp. 22I-234. ISSN: 2792-3967 
La Asociación de Coros y Danzas de Cieza que realiza el Festival Internacional de Folklore en el Segura desde el año 1989, realizan en el 2020 un festival sin edición, aunque tocaría la $32^{\circ}$ edición- con formato on line en donde han participado once grupos representando a Bielorrusia, Filipinas, Bolivia, Georgia, Sudáfrica, Turquía, Perú y España según Jesús Saorín. Ha tenido una duración de seis días con la realización de diferentes actividades como talleres infantiles, tertulias y dos sesiones de actuaciones de los grupos participantes. Este año 2021 se ha suspendido el festival sin realizar ninguna actividad de forma virtual y tienen puestas todas sus esperanzas de poder realizar en 2022 una nueva edición.

Por su parte, Coros y Danzas Despertar El Ayer, aplazó su 34 edición del Festival Internacional de Folklore de Villanueva de Alcardete para 2021. Un festival que surgió en 1986 y que tras su aplazamiento en 2020 se vuelve a realizar de forma presencial en 2021 reduciéndose el número de grupos participantes de cuatro a tres.

En definitiva, los festivales de folklore no han desaparecido, simplemente muchos han suspendido sus ediciones por la crisis sanitaria. Otros han llevado a cabo ediciones on line y aquellos que han realizado ediciones de forma presencial durante la pandemia han visto como se han reducido el número de actividades desarrolladas con respecto a ediciones anteriores. También se ha reducido el número de agrupaciones participantes. $Y$ al reducirse el aforo, las agrupaciones se replantearon la emisión del festival en streaming para llegar a un mayor público.

\section{Reflexiones |}

La COVID-19 paralizó el sector cultural pero los colectivos de folklore a través de diferentes fórmulas han intentado crear contenidos que fueran consumidos por el público a la vez de mantener activos a sus componentes. Por ello, podemos decir que la maquinaria de las agrupaciones de folklore no ha parado durante la pandemia porque han tenido que reinventarse, creando así nuevos escenarios en torno a la música y danza tradicional donde la difusión ha predominado de manera telemática, creando incluso productos que aún pueden seguir visualizándose.

En general, siempre han estado dispuestos a retomar sus actividades (festivales, cursos, ensayos) teniendo siempre en cuenta las medidas preventivas y la evolución de la pandemia en sus territorios, suspendiendo en varias ocasiones sus actividades y retomándolas cuando ha sido posible para proteger la salud de sus componentes.

Pero en este tipo de colectivos aún existe miedo al contagio, pues cuando se han retomado los ensayos, el índice de participación, en general, ha sido bajo, incluso no pudiéndose realizar algunas actuaciones por no contar con integrantes suficientes.

El hecho de suspender actividades en las asociaciones de folklore está causando un grave perjuicio, ya no solo económico, sino también organizativo, en la medida en que los integrantes del colectivo, al no haber una rutina de ensayos, buscan otras actividades para ocupar su tiempo de ocio, y caen en la comodidad y el desánimo, adquiriendo otros hábitos de ocio y estableciendo nuevas formas de relacionarse por lo que está costando 
trabajo volver a la rutina de ensayos y tener el mismo índice de participación anterior a la pandemia.

La parte económica está siendo un problema sobre todo para todas aquellas asociaciones que pagan el alquiler de su local de ensayo, pues los ingresos han disminuido, porque al no haber actividades presenciales, muchos socios han solicitado la baja mientras no se reanude la actividad, con lo que supone en muchos casos dificultad de pago de las rentas de los locales. Todo ello, unido a que tampoco se realizan actuaciones ni se contrata al grupo para algún evento, las arcas de las agrupaciones están bajo mínimos.

Esperemos que esta situación no se alargue mucho en el tiempo y poco a poco los colectivos de folklore puedan comenzar a retomar sus actividades con normalidad porque de lo contrario, una agrupación sin ensayos, sin actividades, sin actuaciones, sin festivales, sin integrantes que se relacionen dentro de la asociación haciendo que sea un colectivo vivo, podrían llevarla a desaparecer y con ella, todos aquellos bienes culturales inmateriales que atesoran en ella y que forman parte del Patrimonio Cultural Inmaterial.

\section{Referencias}

Arce Solarana, J. (2021). Entrevista realizada al Director Artístico de Grupo de Danzas San Sebastián de Reinosa el 6 de agosto de 2021.

Cobo Franco, V. J. (2021). Aproximación a una primera distribución geográfica de los colectivos dedicados al folklore en España. Revista Danzaratte (14), 73-86.

Colomer Sánchez, A. (2021). COVID-19, arte y cultura: crear, construir y generar nuevas realidades desde el artista. Studia Humaninatis Journal (I), 238-248.

INAEM (2021). Guía de buenas prácticas para el reinicio de la actividad escénica y musical en España, Ministerio de Cultura y Deporte. Gobierno de España.

Martínez López, Natalia (2021). Entrevista realizada a la secretaria de la Asociación Foclórica e Cultural Orballo el 10 de agosto de 2021.

REAL DECRETO 463/2020, de 14 de marzo, por el que se declara el estado de alarma para la gestión de la situación de crisis sanitaria ocasionada por el COVID-19.

REAL DECRETO LEY 21/2020, de 9 de junio, de medidas urgentes de prevención, contención y coordinación para hacer frente a la crisis sanitaria ocasionada por el COVID-19, de la Jefatura del Estado.

Sanz, Juan Luis (2021). Entrevista realizada al subdirector de la Agrupación de Coros y Danzas Despertar el ayer el 16 de agosto de 2021.

Saorín Piñera, Jesús (2021). Entrevista realizada al presidente de la Asociación de Coros y Danzas de Cieza el 21 de agosto de 2021. 
UNESCO (2003). Convención para la Salvaguarda del Patrimonio Cultural Inmaterial, París.

Valle Peruledo, Julio César (2021). Entrevista realizada al presidente de la Asociación de Coros y Danzas Rosa del Azafrán el 8 de agosto de 2021.

\section{| Nota biográfica |}

Víctor Cobo Franco es Licenciado en Publicidad y Relaciones Públicas, así como en Comunicación Audiovisual por la Universidad Complutense de Madrid. Máster Universitario en Artes Escénicas por la Universidad Rey Juan Carlos de Madrid y Postgrado Especialista en Gestión de la Comunicación en Organizaciones Culturales: Artes Escénicas y Música por la Universidad Complutense de Madrid. Actualmente es Profesor Técnico de Formación Profesional de Producción en Artes Gráficas en el IES Islas Filipinas (Madrid). Es director del Grupo de Coros y Danzas La Nacencia del Centro Extremeño en Alcalá de Henares. Coordina el Festival Cervantino de Música y Danza Tradicional realizado en Alcalá de Henares. Su línea de investigación se centra en los colectivos dedicados a salvaguardar la danza tradicional. 